\title{
Linking Ethical Leadership to Work Engagement: The Effects of Person-Group Fit and Person-Job Fit
}

\author{
JING-FUH YANG $^{1}$, CHU-CHUN FENG ${ }^{2 *}$, PING-HSUN FENG $^{3}$ \\ Department of Marketing and Distribution Management, National Kaohsiung University of Science \\ and Technology, TAIWAN \\ College of Management, National Kaohsiung University of Science and Technology, Taiwan \\ Department of Medical Imaging, Chi Mei Medical Center, TAIWAN \\ Department of Anesthesiology, Chi Mei Hospital, Liouying, TAIWAN
}

\begin{abstract}
The study of ethical leadership involving corporate leaders has gained importance in recent years. This research investigated the link between ethical leadership and performance using data from the medical center in Taiwan. Drawing on person-environment fit theory, we examined the mediating roles of persongroup fit and person-job fit in the relationship between ethical leadership and work engagement. A convenience sampling was used to collect 447 valid questionnaires, and structural equation modeling was used for analysis and testing. Results revealed that ethical leadership is positively related to work engagement. Further, $\mathrm{P}-\mathrm{G}$ fit and $\mathrm{P}-\mathrm{J}$ fit mediate the relationship between ethical leadership and work engagement. Finally, implications for theory and practice are discussed.
\end{abstract}

Key-Words: - ethical leadership, person-group fit, person-job fit, work engagement

Received: January 17, 2020. Revised: July 1, 2020. Accepted: July 8, 2020. Published: July 9, 2020.

\section{Introduction}

In today's dynamic and increasingly challenging healthcare environment that aims to create an effective and inspiring work environment, ethical leadership has been known as the importance factor. Ethical leadership is described as a motivational process through which leaders' behavior affects the attitudes and behavior of their followers [11]. Ethical leadership has become a topic that has attracted a high level of attention from scholars and practitioners of human resource management and organizational behavior [8]. Several academic studies have explored the relationships between ethical leadership and theoretically expected outcomes including commitment, justice, trust, job satisfaction, and followers' organizational citizenship behavior. Studies have proven the positive influence that ethical leadership has on employee performance. However, only a few studies have investigated the relationships between ethical leadership and work engagement, especially in the medical industry. Therefore, the purpose of our research is to explore the underlying processes and motivational mechanisms by linking ethical leadership with work engagement [44].

Work engagement is defined as a "positive, fulfilling, and work-related state of mind that is characterized by vigor, dedication and absorption" [34]. Individuals who are engaged in their work have high levels of energy and enthusiasm and are completely immersed in their work activities. Job demands-resources (JD-R) theory [41] is one of the most widely used theories to explain work engagement. The JD-R theory focuses on job characteristics, employee behaviors, and personal resources. Subsequently, we develop variables to show that person-group fit ( $\mathrm{P}-\mathrm{G}$ fit) and person-job fit (P-J fit) are important resources that influence levels of work engagement. Person-environment fit (P-E fit) had long been a research topic of interest among industrial and organizational psychologists [29]. This study of P-E fit that offers a framework as a specific type of the match between corresponding person and environment dimensions [19], including $\mathrm{P}-\mathrm{G}$ fit, $\mathrm{P}-\mathrm{J}$ fit, person-organization fit ( $\mathrm{P}-\mathrm{O}$ fit), and person-supervisor fit ( $\mathrm{P}-\mathrm{S}$ fit). 
The results of the current study suggest that different types of fit have different effects on workrelated outcomes [32]. However, despite extensive research, most previous studies had largely focused on the relationship between a single rather than multiple types of fit perceptions (e.g. $\mathrm{P}-\mathrm{O}$ fit, $\mathrm{P}-\mathrm{G}$ fit, $\mathrm{P}-\mathrm{J}$ fit, and $\mathrm{P}-\mathrm{S}$ fit) with outcomes. To fill these research gaps, our study simultaneously examines the multidimensional effects of different fit perceptions on work engagement. We combine $\mathrm{P}-\mathrm{G}$ fit (conceptualized as supplementary fit and complementary fit) and P-J fit (conceptualized as needs-supplies fit and demand-abilities fit) as predictors of work engagement. We specifically focus on these two types of fit because they impact group or job and are useful in the inquiry into ethical leadership and work engagement linkage. P$\mathrm{G}$ fit is one of the most under-researched areas of $\mathrm{P}$ $\mathrm{E}$ fit [38], given that work teams are becoming widely used in the corporate world, especially the medical industry. The role of effective communication and team collaboration are crucial in helping improve patient safety and promoting positive patient outcomes. Healthcare providers must work closely with one another to provide wellorganized comprehensive care as $\mathrm{P}-\mathrm{G}$ fit becomes an increasingly relevant construct [30]. P-J fit refers to the match between an employee's skills and abilities and those required to effectively perform one's job [27]. It emphasizes that employees possess the technical expertise to perform their assigned jobs and make valuable contributions [44] in the field of healthcare. Moreover, we advance insights by investigating the mediating roles of $\mathrm{P}-\mathrm{G}$ fit and $\mathrm{P}-\mathrm{J}$ fit in the relationship between ethical leadership and work engagement. Against this backdrop, the study examines the role of ethical leadership in promoting work engagement and the mediating roles of $\mathrm{P}-\mathrm{G}$ fit and $\mathrm{P}-\mathrm{J}$ fit in enhancing the validity and precision of ethical leadership for work engagement.

This study aims to examine the relationship between ethical leadership and various work-related outcomes. The following contributions to extant literature are presented. First, anchoring on the P-E fit framework, this study invokes $\mathrm{P}-\mathrm{G}$ fit and $\mathrm{P}-\mathrm{J}$ fit to determine how ethical leadership affects work engagement. We seek to establish the linkages between ethical leadership, $\mathrm{P}-\mathrm{G}$ fit, $\mathrm{P}-\mathrm{J}$ fit, and work engagement. Second, this study examines not only the direct relationships above but also the effect of $\mathrm{P}-\mathrm{G}$ fit and $\mathrm{P}-\mathrm{J}$ fit as a mediator, thereby shedding light on the mechanism by which ethical leadership affects work engagement. Third, the results can enable companies to improve employee work engagement and deploy ethical leaders to maximize the organization benefits.

\section{Theoretical Background and Hypotheses}

Figure 1 illustrates the hypothesized research framework where the direct effects of ethical leadership on work engagement, $\mathrm{P}-\mathrm{G}$ fit, and P-J fit are first examined. Subsequently, other relationships and mediating effects among these factors are investigated. The key variables and specific hypotheses regarding the above relationships are described in the following sections (see Figure 1).

\subsection{Ethical leadership and work engagement}

\section{Ethical leadership}

Brown and Treviño [10] argued that ethical behavior is the essence of effective leadership. That is, organizational leaders have principal roles in establishing ethical guidelines that enhance employee attitude and behavior. Ethical leadership is defined as "the demonstration of normatively appropriate conduct through personal actions and interpersonal relationships, and the promotion of such conduct to followers through two-way communication, reinforcement, and decisionmaking" [9]. From this definition, ethical leadership flows along two components: the "moral person" and the "moral manager". The former is presumed to be people with high moral values such as trustworthiness, honesty, motivation, integrity, and justice [17]. Specifically, ethical leaders become credible and attractive role models upon demonstrating integrity and setting high ethical standards for themselves and other employees [9]. Second, "moral managers" create codes and principles for others and highlight the importance of ethics by communicating strong ethical messages and use rewards and punishments to guide ethical behavior [9]. Furthermore, Brown et al. [9] stated that the roots of ethical leadership lie in two different theories, namely, social learning theory and social exchange theory. The former theorizes that leaders must be attractive and credible role models to be considered ethical by their followers [9]. The latter postulates that social exchange relationships between leaders and their subordinates develop from interactions, which over time provide for mutually and rewarding transactions and relationships [10]. 


\section{Work engagement}

Kahn [26] was one of the first to theorize regarding work engagement, which is characterized by vigor, dedication, and absorption [37]. Vigor refers to high levels of energy and mental resilience at work, willingness to invest effort in one's job, and persistence in the face of difficulties. Dedication refers to strong involvement in one's job, and the experience of a sense of significance, enthusiasm, inspiration, pride, and challenge. Absorption refers to full concentration and deep engagement in one's job, whereby time passes quickly and detaching oneself from work is difficult. Engaged employees are more likely to work hard and expend discretionary effort in their jobs, thereby improving production and showing better in-role task performance. Work engagement is a critical element in maintaining the organizational vitality, survival, and profitability [2]. In other words, companies with highly engaged employees experience enhanced customer satisfaction, profits, and employee productivity. Moreover, engaged workers are more inclined to help their colleagues. At the team level, work engagement is found positively associated with performance [42].

Ethical leaders play a significant role in intrinsically motivating their followers to deliver work engagement. Through their demonstrated behavior, ethical leaders not only change employee perception toward work [10] but also influence followers to exert extra effort. That is, followers tend to adopt work engagement when they perceive their leaders as acting ethically. In addition, a moral manager influences follower attitude through leadership behavior [9]. Thus, understanding in which situation ethical leadership can enhance followers' work engagement is important for managers. In summary, ethical leadership behavior plays an important role in promoting employee attitude and behavior [9], which is a main element of work engagement [7]. Employees are likely and willing to exert certain extra effort [9] and become more actively engaged in their work. Based on the above arguments, we propose the following hypothesis:

H1: Ethical leadership is positively related to work engagement.

\subsection{Ethical leadership, P-G fit, and P-J fit}

\section{P-G fit}

$\mathrm{P}-\mathrm{G}$ fit is defined as "the compatibility between individuals and their work groups" [30]. Team members require appropriate attributes to work effectively with each other [45]. In other words, $\mathrm{P}$ $\mathrm{G}$ fit is best conceptualized as the congruence between a combined set of team elements, thereby producing relatively higher team effectiveness [15]. $\mathrm{P}-\mathrm{G}$ fit is most strongly related to group-oriented outcomes such as feelings of cohesion and colleague satisfaction. $\mathrm{P}-\mathrm{G}$ fit must be considered in the selection for team membership. Individuals become happier and more successful in their workplace when their personality traits match environment characteristics.

\section{P-J fit}

$\mathrm{P}-\mathrm{J}$ fit is defined as the match between characteristics of the person and of the job or task [18]. P-J fit focuses on employees with the technical skills to perform job requirements and make valuable contributions. $\mathrm{P}-\mathrm{J}$ fit comprises two key components [20], including demands-abilities (DA) fit and needs-supplies (NS) fit. DA fit is the congruence between individual knowledge, skills and abilities, and work demands. NS fit is the congruence between employee needs and the supplies that come from their work [1]. DA fit has a stronger focus on the job, whereas NS fit focuses more on employees. According to the psychological needs fulfillment paradigm underlying complementary fit and P-J fit in particular [18], employees express increased positive attitudes at work when their needs are fully addressed [33].

Ethical leadership creates opportunities for employees to participate in decision-making, which allows employees to improve team cohesion and form collective team identification. Thus, ethical leadership can satisfy the follower needs for belongingness and thus enhance employee $\mathrm{P}-\mathrm{G}$ fit. Employees with good $\mathrm{P}-\mathrm{G}$ fit are more likely to establish strong connections between helping their colleagues and the organization as a whole. In addition, ethical leaders focus on individual employee development, providing followers not only the resources required to complete their jobs but also enhancing their capabilities to fulfill job demand. Thus, ethical leadership can improve employee DA fit and NS fit. We reason that ethical leadership has a positive effect on $\mathrm{P}-\mathrm{J}$ fit. That is, employees who perceive a high level of ethical leadership are more willing to exert positive effort into their jobs, which in turn increases their P-J fit. Based on the above arguments, we propose the following hypotheses:

H2: Ethical leadership is positively related to $P-G$ fit.

H3: Ethical leadership is positively related to $P-J$ fit. 


\subsection{P-G fit, $P-J$ fit, and work engagement} $\mathrm{P}-\mathrm{G}$ fit is considered the key element that can predict employee performance, especially in the team context. Personality similarities help facilitate communication among employees and foster social integration [31]. Individuals who perceive their similarity to other colleagues tend to perform more positive work behaviors and attitudes, such as higher work engagement, job satisfaction, organizational commitment, work performance, and lower turnover intention [1]. Hence, effective use of $\mathrm{P}-\mathrm{G}$ fit improves team cohesion in the workplace and creates effectively functioning work units.

In addition, $\mathrm{P}-\mathrm{J}$ fit is positively associated with employee work engagement [13]. DA fit and NS fit are also found to be positively related to work engagement. Shuck et al. [39] recently reported similar findings regarding the effect of job fit on employee engagement. Compared with their peers, employees who perceive high levels of $\mathrm{P}-\mathrm{J}$ fit are more willing to work with enthusiasm for their jobs, which in turn increases their level of work engagement. That is, a strong match between employees and their job description means that they possess sufficient resources to exert into their work [25]. Therefore, to maintain satisfied, motivated, and highly committed employees, organizations tend to select employees on the basis of $\mathrm{P}-\mathrm{G}$ fit and $\mathrm{P}-\mathrm{J}$ fit [1]. Individuals that are skilled at their jobs and have congruent characteristics with those of their work group members are more likely to have high levels of work engagement than their peers. Employees with high $\mathrm{P}-\mathrm{G}$ fit and $\mathrm{P}-\mathrm{J}$ fit are also more helpful to their co-workers and the organization as a whole. In addition, these employees are likely to have high levels of in-role and extra-role performance [43]. P-G fit and P-J fit are thus associated with high levels of work engagement, specifically in direct proportions. Based on the above arguments, we propose the following hypotheses:

H4: $P-G$ fit is positively related to work engagement.

H5: $P-J$ fit is positively related to work engagement.

\subsection{Mediating roles of $P-G$ fit and $P-J$ fit}

The above relationships between ethical leadership, $\mathrm{P}-\mathrm{G}$ fit, $\mathrm{P}-\mathrm{J}$ fit, and work engagement are important. In addition, among all types of fit, $\mathrm{P}-\mathrm{G}$ fit and $\mathrm{P}-\mathrm{J}$ fit exert the most significant effect on job performance [29]. The present study enriches this approach by hypothesizing mediating relationships in which $\mathrm{P}-\mathrm{G}$ fit and $\mathrm{P}-\mathrm{J}$ fit mediate the relationship between ethical leadership and work engagement. Employee perceptions of congruence with their work group and their jobs likely foster their fit perceptions with the organization as a whole, resulting in increased levels of work engagement. Through ethical leadership, group members may have similar perceptions of shared group values and the adequacy of team knowledge, skills, and abilities to meet task demands [28], thus resulting in better work engagement. Therefore, we contend that ethical leadership enhances employee perceptions of $\mathrm{P}-\mathrm{G}$ fit and $\mathrm{P}-\mathrm{J}$ fit, which in turn increase their work engagement. Based on the above arguments, we propose the following hypotheses:

H6: Employee perceptions of $P-G$ fit mediate the relationship between ethical leadership and work engagement.

H7: Employee perceptions of $P-J$ fit mediate the relationship between ethical leadership and work engagement.

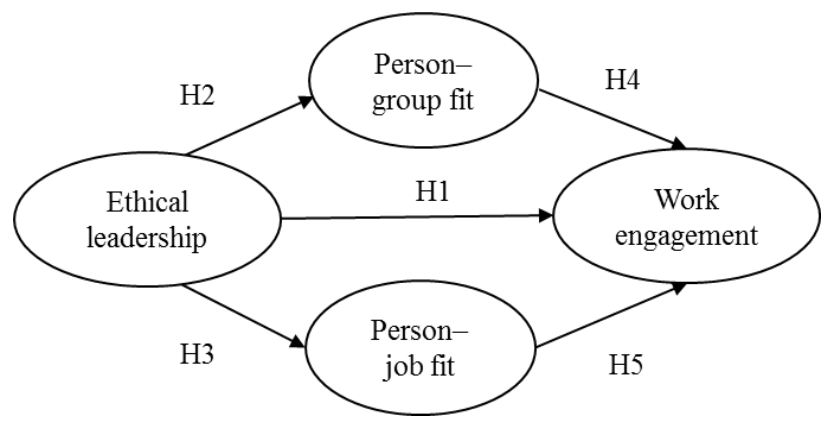

Figure1. Conceptual Model

\section{Research method}

\subsection{Sample and procedures}

The hypotheses were tested empirically by collecting data from employees of a medical center in Taiwan. In this study, the target respondents included nurses, radiologic technologists, pharmacists, medical administrators, and other medical staff. We contacted an administration personnel from a 12-unit hospital to be our contact person and aid in the distribution and collection of questionnaires. A return envelope was also provided to each respondent to seal in the completed questionnaire and return directly to the researchers. No identifying participant information was recorded or stored to ensure privacy and increase response rate.

All question items are translated into Chinese through the back-translation technique. Senior researchers with expertise on the subject matter reviewed the survey questionnaire to ensure its proper translation without ambiguity. Before conducting the survey, a pilot test was performed by 
distributing the questionnaire to 30 graduate students. The instrument is refined by clarifying misrepresentations of the original meaning. Moreover, non-response bias was tested by comparing the answers of late responders to those of early ones [3]. Subsequently, the survey data were collected for approximately two months and yielded 500 completed questionnaires. After excluding 53 invalid forms, 447 questionnaires were finally used for data analysis. Accordingly, the response rate was $89.4 \%$. Regarding the sample demographics, $58 \%$ were female and $42 \%$ were male; average age was 38 years; average organizational tenure was 12 years; and $89 \%$ held university degrees.

\subsection{Measures}

All the items in each measure were scored on a fivepoint Likert scale, ranging from 1 (strongly disagree) to 5 (strongly agree).

Ethical leadership was measured using the 10-item scale developed and validated by Brown et al. [9] The items included "Listens to what employees have to say" and when making decisions the employee asks "What is the right thing to do". Cronbach's $\alpha$ for this scale was 0.88 .

$\mathrm{P}-\mathrm{G}$ fit was measured using five items from Newman, A. et al. [35]. Sample items included "My co-workers and I share the same workplace ethics" and "Other employees in my organization appreciate that I have distinct work-related goals". Cronbach's $\alpha$ for this scale was 0.86 .

$\mathrm{P}-\mathrm{J}$ fit was measured using five items modified by Cable and DeRue [12]. Sample items included "The match is very good between the demands of my job and my personal skills" and "The attributes that I look for in a job are fulfilled very well in my present job". Cronbach's $\alpha$ for this scale was 0.92 .

Work engagement was measured with 10 items from the Utrecht Work Engagement Scale [16], which had its factorial validity previously demonstrated [5]. The instrument consists of three subscales to assess vigor, dedication, and absorption. Vigor was assessed with four items (e.g., "At my work, I feel bursting with energy"; "When I get up in the morning, I feel like going to work"). Dedication was measured with three items (e.g., "I am enthusiastic about my job"; "I find the work that I do is full of meaning and purpose"). Absorption was assessed with three items (e.g., "I am immersed in my work"; "When I am working, I forget everything else around me"). Cronbach's $\alpha$ for this scale was 0.96 .

\subsection{Control Variables}

Several control variables included [35] in the analysis are gender, age, and organization tenure. Education level is also included as a control variable.

\section{Results}

\subsection{Reliability and validity}

Confirmatory factor analysis (CFA) was adopted to test the scale reliability, convergent validity, and discriminant validity. Cronbach's $\alpha$ coefficients of latent constructs were all suitable (0.86-0.96), indicating acceptable internal consistency. In addition, the composite reliabilities (CR) of study constructs ranged $0.86-0.96$, exceeding the recommended threshold of 0.70 [22]. These values indicated adequate internal consistency of multiple indicators for each model construct. As for convergent validity, factor-loading coefficients of the CFA above the minimum standard of 0.50 [4] and over 0.70 would be excellent. All average variance extracted (AVE) values ranged from 0.660.85 , exceeding the recommended threshold of 0.50 [21], reflecting convergent validity. We also assessed discriminant validity by comparing the square of the correlation parameters with the AVE. The square root of each AVE value exceeded the correlation coefficients between constructs and ranged $0.81-0.96$, providing sufficient discriminant validity. In summary, each construct met the required criteria and indicated that the scale had reliability and validity.

\subsection{Descriptive Statistics}

Table 1 shows descriptive statistics means, standard deviations, internal consistencies (Cronbach's $\alpha$ ), and correlations among all study variables.

Table 1 Descriptive statistics and correlations

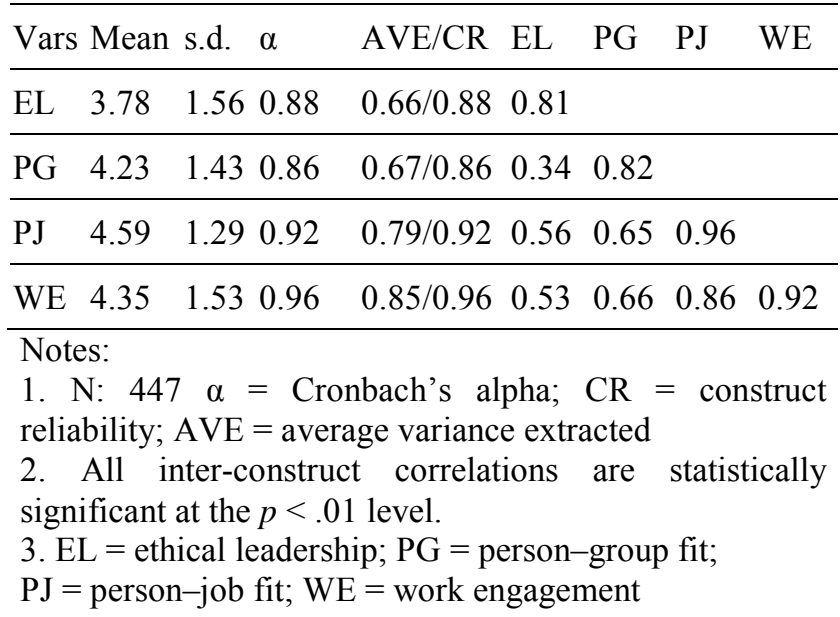




\subsection{Measurement structure model}

We used AMOS 20.0 to carry out an overall measurement model test to assess the reliability and validity of the latent variables in the model. The fit indices of the structural path model results are as follows: $\chi 2 / d f=3.898$, RMR $=0.016$, RMSEA $=$ $0.081, \mathrm{GFI}=0.849, \mathrm{AGFI}=0.813, \mathrm{IFI}=0.942, \mathrm{CFI}$ $=0.941$ (see Table 2). Referring to $\mathrm{Hu}$ and Bentler (1999) [24], these values are over 0.80 and thus indicate acceptable model fit. Structural equation modeling was used to validate and analyze the hypotheses (see Figure 2 and Table 3).

Ethical leadership positively affects work engagement ( $\beta=0.435, t=4.956)$, supporting $\mathrm{H} 1$. Ethical leadership positively affects $\mathrm{P}-\mathrm{G}$ fit $(\beta=$ $0.473, t=8.635)$ and $\mathrm{P}-\mathrm{J}$ fit $(\beta=0.641, t=11.517)$, supporting $\mathrm{H} 2$ and $\mathrm{H} 3$ respectively. That is, as ethical leadership increases, $\mathrm{P}-\mathrm{G}$ fit and $\mathrm{P}-\mathrm{J}$ fit also increase. $\mathrm{P}-\mathrm{G}$ fit has significant positive effects on work engagement $(\beta=0.208, t=5.616)$, confirming H4. P-J fit significantly affects work engagement $(\beta$ $=0.795, t=12.17$ ), confirming $\mathrm{H} 5$. Therefore, as $\mathrm{P}-$ $\mathrm{G}$ fit and $\mathrm{P}-\mathrm{J}$ fit increase, work engagement also increases.

Table 2: The Results of the goodness of Fit Test of Structural Equation Model

\begin{tabular}{lccc}
\hline Fit index & $\begin{array}{c}\text { Cut-off } \\
\text { value }\end{array}$ & Results & $\begin{array}{c}\text { Goodness } \\
\text { of fit }\end{array}$ \\
\hline$\chi^{2 / d f}$ & $2 \sim 5$ & 3.898 & Acceptable \\
RMSEA & $\leq 0.08$ & 0.079 & Acceptable \\
GFI & $\geq 0.80$ & 0.849 & Acceptable \\
AGFI & $\geq 0.80$ & 0.813 & Acceptable \\
IFI & $\geq 0.90$ & 0.942 & Acceptable \\
CFI & $\geq 0.90$ & 0.941 & Acceptable \\
\hline
\end{tabular}

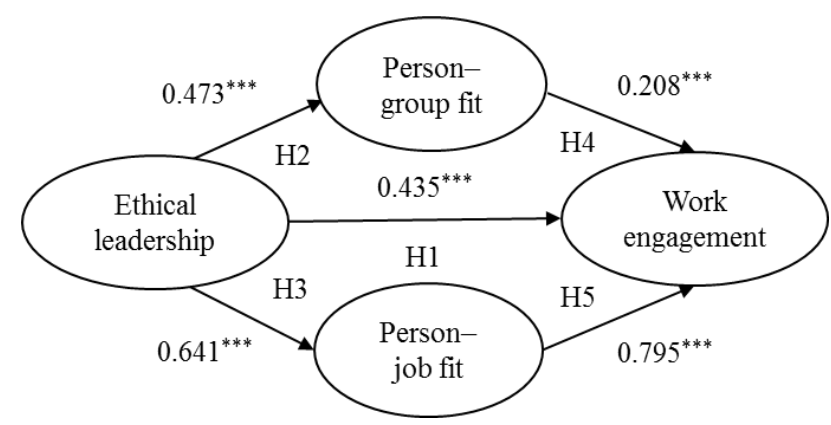

Figure2. Structural model with estimated path coefficients

Notes: ${ }^{* * *} p<.001$.

Solid lines indicate a statistically significant path (support)
Table 3: Path coefficients and their significance

\begin{tabular}{llcrl}
\hline & \multicolumn{1}{c}{ Path } & $\begin{array}{c}\text { Std. path. } \\
\text { coefficient }\end{array}$ & $\begin{array}{c}\mathrm{t} \\
\text { Statistic }\end{array}$ & Result \\
\hline $\mathrm{H}_{1}$ & EL $\rightarrow \mathrm{WE}$ & $0.435^{* * *}$ & 4.96 & Supported \\
$\mathrm{H}_{2}$ & EL $\rightarrow \mathrm{PG}$ & $0.473^{* * *}$ & 11.52 & Supported \\
$\mathrm{H}_{3}$ & EL $\rightarrow \mathrm{PJ}$ & $0.641^{* * *}$ & 8.64 & Supported \\
$\mathrm{H}_{4}$ & $\mathrm{PG} \rightarrow \mathrm{WE}$ & $0.208^{* * *}$ & 5.62 & Supported \\
$\mathrm{H}_{5}$ & $\mathrm{PJ} \rightarrow \mathrm{WE}$ & $0.795^{* * *}$ & 12.17 & Supported \\
\hline
\end{tabular}

Notes:

1. $E L=$ ethical leadership; $P G=$ person-group fit;

$\mathrm{PJ}=$ person-job fit; $\mathrm{WE}=$ work engagement

2. ${ }^{* * *} p<.001$.

\subsection{Mediation effects of $P-G$ fit and $P-J$ fit.}

We used model 4 of the PROCESS macro (Hayes, 2017) [23] to test the mediating effects of $P-G$ fit and $\mathrm{P}-\mathrm{J}$ fit. The analyses were conducted through bootstrapping $(5,000$ bootstrap samples) with $95 \%$ bias-corrected confidence intervals and indicated indirect positive effects. The results of mediation effects were found as follows: $\mathrm{P}-\mathrm{G}$ fit mediated the effect of ethical leadership on work engagement $(\beta$ $=0.19,95 \% \mathrm{CI}=[0.13,0.25]) ; \mathrm{P}-\mathrm{J}$ fit mediated the effect of ethical leadership on work engagement $(\beta$ $=0.50,95 \% \mathrm{CI}=[0.41,0.59])$. An indirect effect excluding zero is considered to be statistically significant [23]. Thus, $\mathrm{P}-\mathrm{G}$ fit and $\mathrm{P}-\mathrm{J}$ fit mediate the indirect positive effects of ethical leadership on work engagement, supporting $\mathrm{H} 6$ and $\mathrm{H} 7$, respectively.

\section{Discussion}

This study has discussed the importance of leadership in medical industry and the relationship between ethical leadership and work engagement through $\mathrm{P}-\mathrm{G}$ fit and $\mathrm{P}-\mathrm{J}$ fit. These results have important implications for theory and practice in medical industry that we outline below.

\subsection{Theoretical implications}

The study makes several important contributions to existing theory and research. First, the results indicate that ethical leadership is related positively and directly to healthcare staffs' perception of their fit within the work group and job characteristics. When leaders display ethical behaviors, healthcare staffs' perceptions of congruence with their work group and their jobs will likely foster their fit perceptions. Second, on the basis of P-E fit theory, this study shows the relationships between ethical leadership and work engagement through a link between $\mathrm{P}-\mathrm{G}$ fit and $\mathrm{P}-\mathrm{J}$ fit. Third, our findings have shown that ethical leadership is positively 
linked to work engagement [14]. In addition, $\mathrm{P}-\mathrm{G}$ fit and $\mathrm{P}-\mathrm{J}$ fit were also positively related to work engagement. In other words, $\mathrm{P}-\mathrm{G}$ fit and $\mathrm{P}-\mathrm{J}$ fit enable employees to alter the task and relational boundaries of their jobs, and thus increase their work engagement. Fourth, our results showed that ethical leadership was positively related to $\mathrm{P}-\mathrm{G}$ fit and $\mathrm{P}-\mathrm{J}$ fit, which expands our understanding of the relationship among ethical leadership, $\mathrm{P}-\mathrm{G}$ fit, and $\mathrm{P}-\mathrm{J}$ fit. A few scholars have tried to combine $\mathrm{P}-\mathrm{G}$ fit and $\mathrm{P}-\mathrm{J}$ fit relationships to comprehend the intertwined dynamics of those two frameworks in the workplace. Work environment is composed of many intricate mechanisms that potentially influence employees' attitudes and behaviors. Our research contributes to existing literature by attempting to examine the relationship among different multidimensional types of fit and how they influence work engagement. Fifth, we argued that a strong fit with an organization meets individual psychological needs, which initiate a motivational process, inducing employees' work engagement. Our results support this proposition as employees who perceived good fit with their organization (including $\mathrm{P}-\mathrm{G}$ fit and $\mathrm{P}-\mathrm{J}$ fit) were likely to demonstrate high levels of work engagement and thus perform better.

Finally, this study makes an important theoretical contribution by examining not only the direct relationship between ethical leadership and $\mathrm{P}-\mathrm{G}$ fit and $\mathrm{P}-\mathrm{J}$ fit, but also the impact of $\mathrm{P}-\mathrm{G}$ fit and $\mathrm{P}-\mathrm{J}$ fit as a mediator, thereby shedding light on the mechanism by which ethical leadership impacts work engagement. Only a few studies have examined the role of $\mathrm{P}-\mathrm{G}$ fit and $\mathrm{P}-\mathrm{J}$ fit as a mediator between ethical leadership and work engagement. The results indicate that ethical leadership is related directly and indirectly (through $\mathrm{P}-\mathrm{G}$ fit and $\mathrm{P}-\mathrm{J}$ fit) to work engagement. $\mathrm{P}-\mathrm{G}$ fit and $\mathrm{P}-\mathrm{J}$ fit partially mediate the effect of ethical leadership fit on work engagement. This mediation suggests that when employees think that their direct supervisors practice high ethical leadership, employees are likely to display high levels of work engagement, especially when they perceive congruence with their work group as well as with the job characteristics. Therefore, managers tend to select employees based on $\mathrm{P}-\mathrm{G}$ fit and $\mathrm{P}-\mathrm{J}$ fit to maintain motivated, satisfied, and highly committed employees.

\subsection{Managerial implications}

This study has several important implications for organizations and supervisors. First, organizations must also hire and retain employees who possess high ethical values to attain and continue sustaining an ethical work environment. In turn, leaders must serve as role models for employees. Leaders that are viewed as ethical can more likely attract and retain employees who adhere to high ethical values. Second, the findings will help managers recognize the importance of ethical leadership, $\mathrm{P}-\mathrm{G}$ fit, and $\mathrm{P}-$ $\mathrm{J}$ fit in the influence of work engagement. Leaders must be role models of good ethic, which may influence employees' behavior. Supervisors with high ethical leadership can enhance work engagement in healthcare workers, which increases hospital efficacy. Specifically, to maintain satisfied, proactive, and highly committed employees, organizations should select employees on the basis of $\mathrm{P}-\mathrm{G}$ fit and $\mathrm{P}-\mathrm{J}$ fit [1]. Employees with high $\mathrm{P}-\mathrm{G}$ fit and $\mathrm{P}-\mathrm{J}$ fit are helpful toward their co-workers and the organization. They are likely to have high levels of in-role and extra-role performance as well [43]. Third, managers could enhance employees' engagement by designing meaningful tasks that include motivating characteristics. Managers also need to implement engagement in human resource management policies and practices, for instance, personnel selection, socialization, performance management, and training and development [2]. Fourth, individuals should proactively look for employment opportunities where they perceive good fit and fair treatment by the organization. This combination is likely to create a good work atmosphere that enables them to fully flourish in their roles. In sum, this important finding tells an important message for the medical industry: a positive ethical leadership style can create a professional, effective, and collaborative work environment, thus strengthening employees' work engagement. Finally, according to JD-R theory [41], job crafting proactive actions, such as increasing job resources, reducing obstructive job demands, and increasing challenging job demands, leads to work engagement [42]. Therefore, job crafting is an effective bottom-up strategy to improve work engagement of healthcare staff, because it can increase the meaning of work and the fit between a person and his organization, That is, job crafting can enhance the likelihood that employees will customize their jobs with personal preferences, styles, and abilities.

\subsection{Limitations and future research}

Although this research provides important implications for academic researchers and practitioners, limitations of this study should also be noted. First, common method biases may be an issue because the data were collected from the same 
source. Potential rating biases may be lessened by collecting data by using different methods in the future. Second, the research model was examined only in the healthcare context, and findings may be limited by the conclusions drawn from a single setting. Thus, future research should establish whether the results are generalizable to different industries and cross-national contexts. Third, a cross-sectional survey was used due to restrictions in study time and funding. Therefore, only the correlations between variables could be investigated and not their causal relationships. Finally, further research could pay attention to other possible different variables to extend the research scope.

\section{References:}

[1] Abdalla, A., Elsetouhi, A., Negm, A., \& Abdou, H, Perceived person-organization fit and turnover intention in medical centers, Personnel Review, Vol.47, No.4, 2018, pp. 863-881.

[2] Albrecht, S. L., Bakker, A. B., Gruman, J. A., Macey, W. H., \& Saks, A. M., Employee engagement, human resource management practices and competitive advantage, Journal of Organizational Effectiveness, Vol.2, No.1, 2015, pp. 7-35.

[3] Armstrong, J. S., \& Overton, T. S., Journal of marketing research, Vol.14, No.3, 1977, pp. 396-402.

[4] Anderson, J. C., \& Gerbing, D. W., Structural equation modeling in practice: A review and recommended two-step approach, Psychological Bulletin, Vol.103, No.3, 2018, pp. 411-423.

[5] Bakker, A. B., Hakanen, J. J., Demerouti, E., \& Xanthopoulou, D, Job resources boost work engagement, particularly when job demands are high, Journal of Educational Psychology, Vol.99, No.2, 2007, pp. 274-284.

[6] Bakker, A. B., \& Demerouti, E., Job demandsresources theory: Taking stock and looking forward, Journal of Occupational Health Psychology, Vol.22, No.3, 2017, pp. 273-285.

[7] Bakker, A. B., Demerouti, E., \& Schaufeli, W, Dual processes at work in a call centre: An application of the job demands-resources model, European Journal of Work and Organizational Psychology, Vol.12, No.4, 2003, pp. 393-417.

[8] Banks, G. C., McCauley, K. D., Gardner, W. L., \& Guler, C. E., A meta-analytic review of authentic and transformational leadership: A test for redundancy, The Leadership Quarterly, Vol.27, No.4, 2016, pp. 634-652.
[9] Brown, M. E., Treviño, L. K., \& Harrison, D. A, Ethical leadership: A social learning perspective for construct development and testing, Organizational Behavior and Human Decision Processes, Vol.97, No.2, 2005, pp. 117-134.

[10] Brown, M. E., Treviño, L. K., Ethical leadership: A review and future directions, The leadership quarterly, Vol.17, No.6, 2006, pp. 595-616.

[11] Bui, H. T., Zeng, Y., \& Higgs, M., The role of person-job fit in the relationship between transformational leadership and job engagement, Journal of Managerial Psychology, Vol.32, No.5, 2017, pp. 373-386.

[12] Cable, D. M., \& DeRue, D. S, The convergent and discriminant validity of subjective fit perceptions, Journal of Applied Psychology, Vol.87, No.5, 2002, pp. 875-884.

[13] Cai, D., Cai, Y., Sun, Y., \& Ma, J., Linking empowering leadership and employee work engagement: the effects of person-job fit, person-group fit , and proactive personality, Frontiers in Psychology, Vol.9, No.1304, 2018, pp. $1-12$

[14] Demirtas, O., Hannah, S. T., Gok, K., Arslan, A., \& Capar, N., The moderated influence of ethical leadership, via meaningful work, on followers' engagement, organizational identification, and envy, Journal of Business Ethics, Vol.145, No.1, 2017, pp. 183-199.

[15] DeRue, D. S., \& Hollenbeck, J. R., The search for internal and external fit in teams, Perspectives on organizational fit, pp. 259-285.

[16] De Bruin, G. P., \& Henn, C. M., Dimensionality of the 9-item Utrecht work engagement scale (UWES-9), Psychological Reports, Vol.112, No.3, 2013, pp. 788-799.

[17] Dhar, R. L., Ethical leadership and its impact on service innovative: The role of LMX and job autonomy, Tourism Management, Vol.57, 2016, pp. 139-148.

[18] Edwards, J. R., Person-job fit: A conceptual integration, literature review, and methodological critique, John Wiley \& Sons, 1991.

[19] Edwards, J. R, 4 person-environment fit in organizations: An assessment of theoretical progress, Academy of Management Annals, Vol.2, No.1, 2008, pp. 167-230.

[20] Edwards, J. R., \& Shipp, A. J., The relationship between person-environment fit and outcomes: An integrative theoretical framework, The Organizational Frontiers Series. Perspectives on Organizational Fit, 2007, pp.209-258. 
[21] Fornell, C., \& Larcker, D. F., Evaluating structural equation models with unobservable variables and measurement error, Journal of Marketing Research, Vol.18, No.1, 1981, 3950.

[22] Hair, J. F., Anderson, R. E., Tatham, R. L., \& Black, W. C, Multivariate data analysis 5th ed., New Jersey, NJ: Printice-Hall., 1998.

[23] Hayes, A. F., Introduction to mediation, moderation, and conditional process analysis: A regression-based approach second edition, Guilford publications, 2017.

[24] Hu, L. t., \& Bentler, P. M., Cutoff criteria for fit indexes in covariance structure analysis: Conventional criteria versus new alternatives. Structural equation modeling, $A$ Multidisciplinary Journal, Vol.6, No.1, 1999, pp. 1-55.

[25] Huang, W., Yuan, C., \& Li, M., Person-Job Fit and Innovation Behavior: Roles of Job Involvement and Career Commitment, Frontiers in Psychology, Vol.10, 2019, pp. 1134-1143.

[26] Kahn, W. A, Psychological conditions of personal engagement and disengagement at work, Academy of management journal Vol.33, No.4, 1990, pp. 692-724.

[27] Kristof-Brown, A. L., Jansen, K. J., \& Colbert, A. E., A policy-capturing study of the simultaneous effects of fit with jobs, groups, and organizations, Journal of Applied Psychology, Vol.85, No.5, 2002, pp. 985-993.

[28] Kristof-Brown, A. L., Park, W.-W., Hong, D.S., \& Shin, Y., Person-group fit : Diversity Antecedents, Proximal Outcomes, and Performance at the Group Level, Journal of Management, Vol.41, No.4, 2018, pp. 11841213.

[29] Kristof-Brown, A. L., Zimmerman, R. D., \& Johnson, E. C., Consequences of individual's fit at work: A meta-analysis of person-job, personorganization, person-group, and personsupervisor fit, Personnel Psychology, Vol.58, No.2, 2005, pp. 281-342.

[30] Kristof, A. L, Person - organization fit: An integrative review of its conceptualizations, measurement, and implications, Personnel Psychology, Vol.49, No.1, 1996, pp. 1-49.

[31] Lam, S. S., Schaubroeck, J., \& Aryee, S., Relationship between organizational justice and employee work outcomes: a cross - national study, Journal of Organizational Behavior, Vol.23, No.1, 2002, pp. 1-18.

[32] Lauver, K. J., \& Kristof-Brown, A., Distinguishing between employees' perceptions of person-job and person-organization fit, Journal of Vocational Behavior, Vol.59, No.3, 2001, pp. 454-470.

[33] Locke, E. A., The nature and causes of job satisfaction. Handbook of industrial and organizational psychology, hicago: RandMc Narlly, 1976.

[34] Mo, S., \& Shi, J., The voice link: A moderated mediation model of how ethical leadership affects individual task performance, Journal of Business Ethics, Vol.152, No.1 2018, pp. 91101.

[35] Newman, A., Schwarz, G., Cooper, B., \& Sendjaya, S., How servant leadership influences organizational citizenship behaviour: The roles of LMX, empowerment, and proactive personality, Journal of Business Ethics, Vol.145, No.1, 2017, pp.49-62.

[36] Piasentin, K. A., \& Chapman, D. S., Subjective person-organization fit: Bridging the gap between conceptualization and measurement, Journal of Vocational Behavior, Vol.69, No.2, 2006, pp. 202-221.

[37] Schaufeli, W. B., Salanova, M., GonzálezRomá, V., \& Bakker, A. B., The measurement of engagement and burnout: A two sample confirmatory factor analytic approach, Journal of Happiness studies, Vol.3, No.1, 2002, pp. 71-92.

[38] Seong, J. Y., \& Kristof-Brown, A. L, Testing multidimensional models of person-group fit, Journal of Managerial Psychology, Vol.27, No.6, 2012, pp. 536-556.

[39] Shuck, B., Reio Jr, T. G., \& Rocco, T. S., Employee engagement: An examination of antecedent and outcome variables, Human Resource Development International, Vol.14, No.4, 2011, pp. 427-445.

[40] Shuck, B, Integrative literature review: Four emerging perspectives of employee engagement: An integrative literature review, Human Resource Development Review, Vol.10, No.3, 2011, pp. 304-328.

[41] Tims, M., Bakker, A. B., \& Derks, D., The impact of job crafting on job demands, job resources, and well-being, Journal of occupational health psychology, Vol.18, No.2, 2013, pp. 230-240.

[42] Tims, M., Bakker, A. B., Derks, D., \& Van Rhenen, W., Job crafting at the team and individual level: Implications for work engagement and performance, Group \& Organization Management, Vol.38, No.4, 2013, pp. 427-454. 
[43] Vogel, R. M., \& Feldman, D. C., Integrating the levels of person-environment fit: The roles of vocational fit and group fit, Journal of Vocational Behavior, Vol.75, No.1, 2009, pp. 68-81.

[44] Werbel, J. D., \& DeMarie, S. M., Aligning strategic human resource management and person-environment fit, Human Resource Management Review, Vol.15, No.4, 2005, pp. 247-262.

[45] Werbel, J. D., \& Johnson, D. J., The use of person-group fit for employment selection: A missing link in person-environment fit, Human Resources Management, Vol.40, No.3, 2001, pp. 227-240.

Creative Commons Attribution License 4.0 (Attribution 4.0 International, CC BY 4.0)

This article is published under the terms of the Creative Commons Attribution License 4.0

https://creativecommons.org/licenses/by/4.0/deed.en_US 